ARTICLE

DOI: $10.1038 /$ s41467-017-00862-4

OPEN

\title{
Characterization of a dual function macrocyclase enables design and use of efficient macrocyclization substrates
}

\author{
Clarissa M. Czekster (10) ${ }^{1}$, Hannes Ludewig (1) ${ }^{1}$, Stephen A. McMahon ${ }^{1}$ \& James H. Naismith 1,2,3,4
}

Peptide macrocycles are promising therapeutic molecules because they are protease resistant, structurally rigid, membrane permeable, and capable of modulating protein-protein interactions. Here, we report the characterization of the dual function macrocyclasepeptidase enzyme involved in the biosynthesis of the highly toxic amanitin toxin family of macrocycles. The enzyme first removes 10 residues from the $\mathrm{N}$-terminus of a 35 -residue substrate. Conformational trapping of the 25 amino-acid peptide forces the enzyme to release this intermediate rather than proceed to macrocyclization. The enzyme rebinds the 25 amino-acid peptide in a different conformation and catalyzes macrocyclization of the $\mathrm{N}$ terminal eight residues. Structures of the enzyme bound to both substrates and biophysical analysis characterize the different binding modes rationalizing the mechanism. Using these insights simpler substrates with only five C-terminal residues were designed, allowing the enzyme to be more effectively exploited in biotechnology.

\footnotetext{
${ }^{1}$ Biomedical Sciences Research Complex, The University of St Andrews, North Haugh, St Andrews K16 9ST, UK. ${ }^{2}$ Biotherapy Centre, Sichuan University, Chengdu, China. ${ }^{3} \mathrm{RCaH}$, Rutherford Appleton Laboratory, Harwell Oxford, Didcot OX11 OFA, UK. ${ }^{4}$ Division of Structural Biology, University of Oxford, Henry Wellcome Building for Genomic Medicine, Old Road Campus, Roosevelt Drive, Headington, Oxford OX3 7BN, UK. Correspondence and requests for materials should be addressed to J.H.N. (email: naismith@strubi.ox.ac.uk)
} 
C yclic peptide macrocycles hold promise in pursuing challenging targets involved in protein-protein interactions implicated in diseases as diverse as cancer and antimicrobial infections ${ }^{1}$. Due to their constrained, pre-organized, and protease-resistant structures, these molecules can modulate key complex macromolecular interactions in a manner that has proven extremely difficult for conventional small molecules ${ }^{1,2}$. In contrast to most linear peptides, many peptide macrocycles are highly cell permeable ${ }^{3}$. Ribosomally synthesized and posttranslationally modified peptides (RiPPs) are a particularly attractive class of macrocycles because their enzymatic synthesis is driven by enzymes working in cascade to process a genetically encoded and highly variable peptide precursor ${ }^{4}$. The peptide precursor can be modified by macrocyclization, oxidation, heterocyclization, hydroxylation, and prenylation in a predictable and scalable manner ${ }^{5}$. The patellamide pathway is a paradigm in this system, in which catalysis and recognition are physically separated in many of the enzymatic steps leading to a unique combination of specificity and promiscuity ${ }^{6}$. The macrocyclase in the patellamide biosynthetic pathway (PatGmac) belongs to the subtilisin class of proteases, requiring a substrate with a Cterminal AYD motif, preceded by heterocyclized cysteine or a proline residue ${ }^{7,8}$. The enzyme is otherwise almost insensitive to the core sequence that becomes the macrocycle and only the thiazoline (or proline) are part of the final product, as the AYD is cleaved off during the reaction. This combination of specificity through the use of disposable tags (leader and/or tail sequences) and promiscuity in the core sequence produces a system that is almost infinitely variable. This has made RiPPs appealing for exploitation in biotechnology. In some RiPPs systems, a linker that can also be varied in both length and composition separates the recognition tag and core peptide ${ }^{9,10}$. Despite the appeal of their promiscuity, the PatG family of macrocyclases face a severe drawback as they are slow ${ }^{11,12}$, although in vitro addition of reductant does increase catalytic efficiency ${ }^{13}$.

In addition to PatG, there are four other broad classes of peptide macrocyclases ${ }^{12,14-16}$ that operate through an acyl enzyme intermediate. The sortase class of enzymes, which catalyze transpeptidation by recognizing a C-terminal LXPTG motif $^{17}$, the butelase enzyme, which is an asparagine/aspartate (Asx) peptide ligase ${ }^{18}$, the NRPS thioesterases ${ }^{19}$ and the prolyl oligopeptidase (POP) class of enzymes. A further important class of macrocyclases is that of the ATP-grasp superfamily, which as the name suggests rely on ATP hydrolysis to drive macrocycliation $^{20}$. The enzymes that catalyze close to traceless peptide bond formation regardless of the peptide sequence-, i.e., only one residue from the precursor peptide recognition tag is carried over to the final cyclic product-are PatGmac family members, butelase, and POP macrocyclases. The POPB from Basidiomycete fungi such as Amanita bisporigera and Galerina marginata (GmPOPB) species have been reported as having $k_{\text {cat }}$ values comparable to butelase, the fastest rate observed for peptide macrocyclisation ${ }^{15,21}$. GmPOPB is the macrocyclase responsible for macrocyclization of amatoxins, eight amino-acid ribosomal peptides with the core sequence IWGIGC(N/D)P. Amatoxins are cyclic peptides further modified by a characteristic sulfoxide cross-link between tryptophan and a cysteine (Fig. 1a), and hydroxylation (the extent of which vary). The genomes of $G$. marginata and other amatoxin producing Amanita species possess more than 50 gene sequences annotated as AMA1 (amatoxin precursors) in which there is considerable diversity in the long Cterminal tail that follows the core sequence ${ }^{15,22}$. Amatoxins are the cause for the toxicity of Amanita and Galerina mushrooms. They are readily absorbed through the gut, and a lethal dose in adults is $<10 \mathrm{mg}^{23}$. Amatoxins are stable to inactivation by either the mammalian digestive tract or cooking, thus consumption of even small numbers of such mushrooms is often fatal. Amatoxin toxicity arises from its accumulation in the liver where it inhibits RNA polymerase II leading to irreparable liver failure ${ }^{23}$. The highly stable and potent toxicity of amatoxins has led to their exploration as warheads for targeted cancer therapy ${ }^{24,25}$. The amatoxin peptide precursor is produced as a 35 amino-acid linear substrate (Fig. 1b), which is first processed to a 25 residue peptide (25mer) by removal of the highly conserved $10 \mathrm{~N}$-terminal amino-acid leader ${ }^{26}$ that is discarded. The newly exposed $\mathrm{N}$ terminal eight residues of the 25 mer product are then macrocyclized and the tail, which is necessary for macrocyclization, is discarded (Fig. 1c). Remarkably, both proteolysis and macrocyclization steps are carried out by the same enzyme, GmPOPB ${ }^{15}$.

We report the functional and structural characterization of GmPOPB and establish the molecular features that determine whether the enzyme catalyzes proteolysis or macrocyclization. Informed by structural and biophysical studies, we have designed a much simpler substrate with fewer C-terminal residues that can be macrocyclized by GmPOPB at synthetically useful rates. The shorter substrate is more cost effective to produce by solid-phase chemical synthesis allowing the generation of more chemically diverse macrocycles, a valuable biotechnological tool.

\section{Results}

Structural biology of Apo and substrate-bound GmPOPB. The apo protein crystals belong to space group $P 2{ }_{1} 2_{1} 2_{1}$, with one monomer in the asymmetric unit. The structure was determined at $2.4 \AA$ resolution by molecular replacement using the $\beta$ propeller domain of the proline oligopeptidase from porcine brain (residues $82-450$, PDB:1h2z) as search model. The refined apo model (PDB:5N4F) includes residues 7-222, 230-695, and 704-726, and the missing regions are presumed to be disordered portions of the protein. The protein contains two domains as observed in other POP enzymes ${ }^{27}$. The domain containing the putative catalytic residues (Ser577, Asp661, His698) comprises residues 1-81 and 450-728, and the other domain is a seven bladed $\beta$-propeller, comprising residues $82-449$ (Fig. 1d). In the apo structure, the two domains are in an "open" conformation, in an arrangement reminiscent of a hinged lid on a bottle. This open conformation has been observed in other POPs in crystal form when free of ligand ${ }^{28,29}$. The catalytic serine sits at the tip of a loop and points toward the $\beta$-propeller domain (Supplementary Fig. 7). The side chain oxygen of Ser 577 is $5.6 \AA$ from the side chain carboxylate of Asp661; His698 is on a loop that is disordered. Ser577 and Asp661 of GmPOPB occupy the same position as Ser554 and Asp641 in the porcine proline oligopeptidase structure ${ }^{30}$.

In order to obtain co-complexes, we mutated each residue of the presumed catalytic triad (mutants S577A, D661A, and H698A) to ensure inactive protein. Crystals were obtained for the 35mer complex for S577A and H698A; with the 25mer substrate S577A and D661A (Table 1). GmPOPB-S577A (the higher resolution of the pair) bound to the full-length substrate (35mer) belongs to space group $P 2_{1}$ with four monomers in the asymmetric unit. For ease of discussion, we split the $35 \mathrm{mer}$ into four regions (Fig. 1b), the 10 residue leader (residues 1-10), the 8 residue core (11-18), 6 residue linker (19-24), and the 11 residue recognition tail (25-35). The refined model (PDB:5N4C) includes residues $6-225$ and $228-727$ of the protein and residues $3-35$ of the peptide (Fig. 1c). The same inactive mutant of GmPOPB was used to obtain a complex structure with the 25 mer substrate; it comprises core (residues 1-8), linker (9-14), and recognition tag (15-25). The refined model includes residues 4-727 of the protein and residues 9-25 (linker and recognition tag) of the peptide (PDB:5N4B). Although we observed residual difference electron 
a

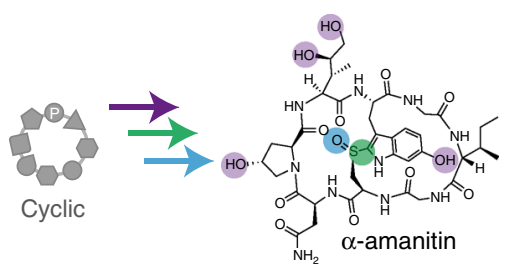

b

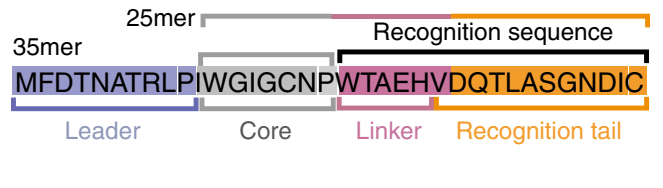

C

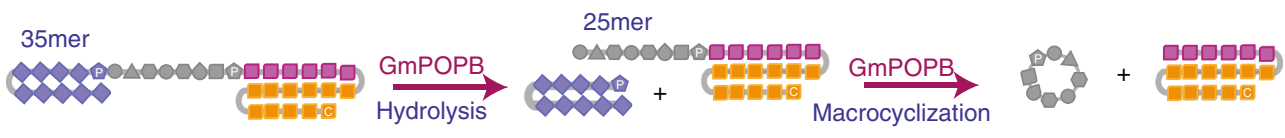

d
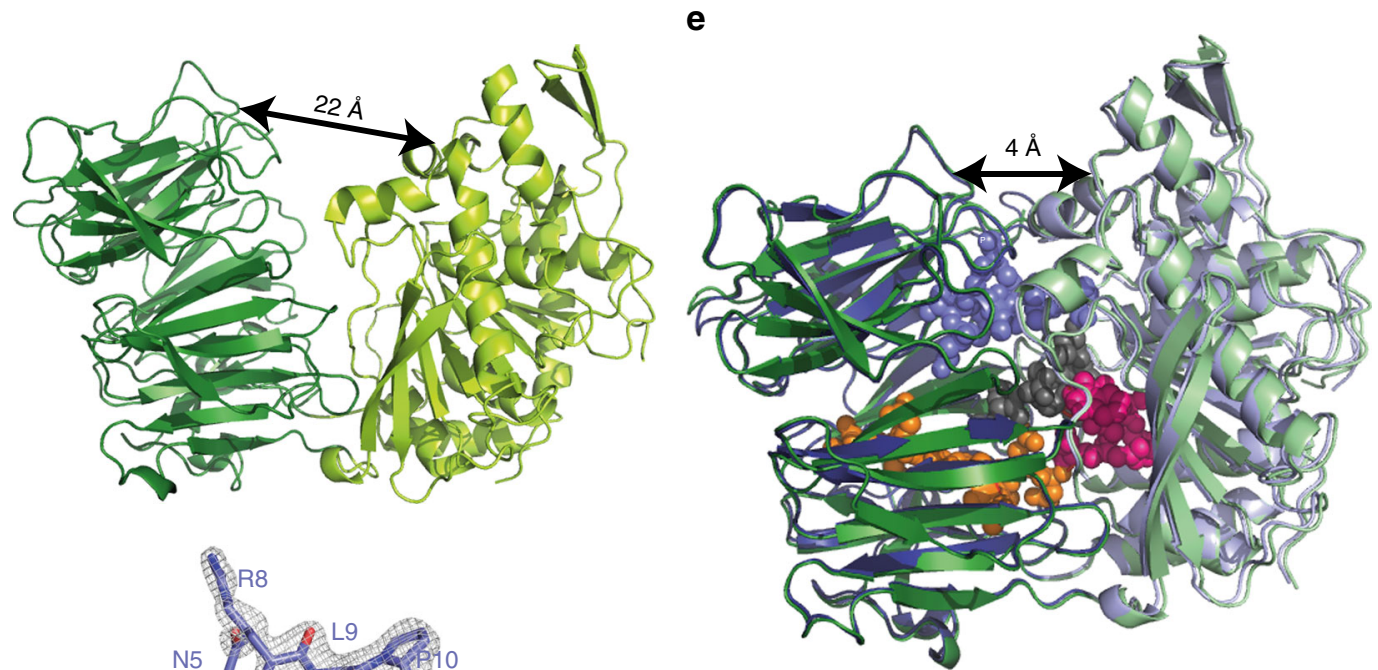

f

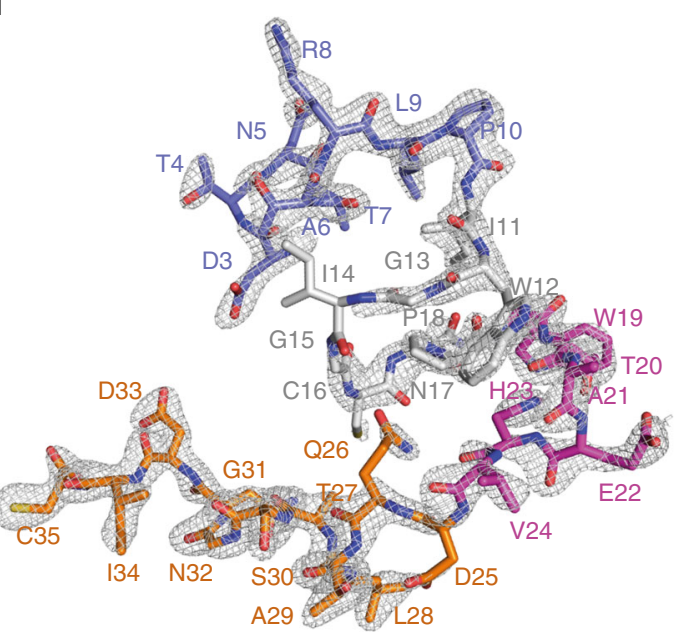

g

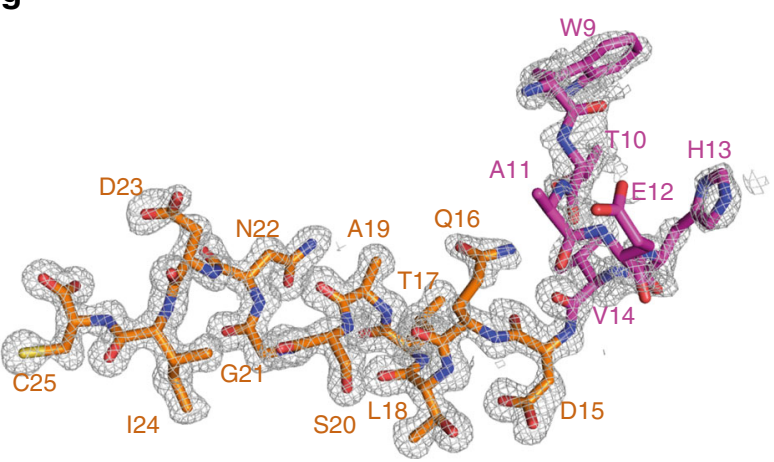

Fig. 1 Amanitin biosynthesis and the role of GmPOPB. a Biosynthesis of $\alpha$-amanitin from the cyclic peptide produced by GmPOPB involves oxidation (blue circle), hydroxylations (purple circles), and cross linking (green circle). Amino acids in the cyclic peptide are depicted as geometrical shapes, and the core proline is labeled. b 35 mer substrate used by GmPOPB to catalyze peptide bond hydrolysis and macrocyclization. Peptide is divided in four regions, leader (blue), core (light gray), linker (magenta), and tail (orange). The color coding for peptide regions for $\mathbf{c}, \mathbf{e}-\mathbf{g}$ follows this. c Scheme of the reactions catalyzed by GmPOPB. d ApoGmPOPB in an open state showing $22 \AA$ separation between the $\beta$-propeller (dark green) and the peptidase domain (light green). e Overlay of $25 \mathrm{mer}$ (blue) and 35mer (green) complexes of S577A. Separation between domains is reduced to $4 \AA$ when peptide is bound. $35 \mathrm{mer}$ peptide is shown in spheres. Darker colors show the $\beta$-propeller domain, while light colors show the peptidase domain. $\mathbf{f} 35 \mathrm{mer}$ peptide bound to GmPOPB-S577A showing electron density ( $2 F \mathrm{~F}-F \mathrm{c}$ contoured at $1 \sigma$ level in gray mesh) for peptide. $\mathbf{g} 25 \mathrm{mer}$ peptide bound to GmPOPB-S577A showing electron density for peptide (2Fo-Fc contoured at $1 \sigma$ level in gray mesh). Supplementary Fig. 11 contains a stereo image depicting electron density maps for the 25mer and 35 mer peptide complexes

density for the $\mathrm{N}$-terminal residues of the $25 \mathrm{mer}$, we were unable to satisfactorily model it. To observe interactions when the catalytic residue Ser 577 is present, we also obtained complex structures of the H698A mutant bound to the 35 mer peptide (PDB:5N4E) and the D661A mutant bound to the 25mer peptide (PDB:5N4D).

In all $35 \mathrm{mer}$ and $25 \mathrm{mer}$ complexes, the enzyme adopts the same "closed" conformation in which the lid (the propeller domain) sits on top of the catalytic domain (Fig. 1e). In both 25mer complexes the N-terminal residues of the substrate (IWGIGCN) are disordered; in the S577A-35mer complex the $\mathrm{N}$-terminal two residues (MF) are missing, while in the H698A complex only the first $\mathrm{N}$-terminal residue is absent. There are no large differences between the protein backbone positions in the complexes with the $35 \mathrm{mer}$ and $25 \mathrm{mer}$ substrates (root mean square deviation (rmsd) of $0.48 \AA$ over $720 \mathrm{C} \alpha$ positions for the S577A structures). There are also no major differences between the H698A-35mer and S577A-35mer complexes, and between 
Table 1 Data collection and refinement statistics

\begin{tabular}{|c|c|c|c|c|c|}
\hline & $\begin{array}{l}\text { GmPOPB- } \\
\text { S577A_25mer }\end{array}$ & $\begin{array}{l}\text { GmPOPB- } \\
\text { D661A_25mer }\end{array}$ & $\begin{array}{l}\text { GmPOPB- } \\
\text { S577A_35mer }\end{array}$ & $\begin{array}{l}\text { GmPOPB- } \\
\text { H698A_35mer }\end{array}$ & apo_GmPOPB \\
\hline \multicolumn{6}{|l|}{ Data collection } \\
\hline $\begin{array}{l}\text { Space group } \\
\text { Cell dimensions }\end{array}$ & $P 2_{1} 2_{1} 2_{1}$ & $P 2_{1} 2_{1} 2_{1}$ & $P 2_{1}$ & $P 2_{1} 2_{1} 2_{1}$ & $P 2_{1} 2_{1} 2$ \\
\hline$a, b, c$ & $99.1,114.7,141.3$ & $99.0,114.9,141.3$ & $100.8,142.6,116.4$ & $99.2,115$ 141. 5 & $90.89,105.62,86.96$ \\
\hline$\alpha, \beta, \gamma$ & $90.0,90.0,90.0$ & $90.0,90.0,90.0$ & $90.0,90.29,90.0$ & $90.0,90.0,90.0$ & $90.0,90.0,90.0$ \\
\hline Resolution & $1.44(1.49-1.44)$ & 1.62 (1.678-1.62) & $2.19(2.268-2.19)$ & $2.9(3.0-2.9)$ & $2.4(2.49-2.4)$ \\
\hline Unique reflections & $288,485(28,320)$ & $204,059(20,188)$ & $163,136(16,107)$ & $32,664(1690)$ & 31,441 (2534) \\
\hline Completeness (\%) & 99.7 (99) & $100(100)$ & $97(96)$ & $97(93)$ & $99(77)$ \\
\hline Mean I/sigma (I) & $9.3(1.3)$ & $6.9(1.0)$ & $6.7(1.2)$ & $6.8(1.7)$ & $14.5(2.2)$ \\
\hline$R$-merge & $0.114(1.01)$ & $0.059(0.69)$ & $0.112(1.0)$ & $0.068(0.53)$ & $0.029(0.56)$ \\
\hline$R$-meas & $0.063(0.588)$ & $0.084(0.98)$ & $0.27(1.5)$ & $0.096(0.52)$ & $0.036(0.72)$ \\
\hline Redundancy & $6.0(6.6)$ & $6.7(6.6)$ & $2.0(2.0)$ & $1.8(1.6)$ & $5.1(3.3)$ \\
\hline \multicolumn{6}{|l|}{ Refinement } \\
\hline Resolution range & 43.3-1.44 & $46.9-1.62$ & $82.3-2.19$ & $32.0-2.9$ & $45.44-2.4$ \\
\hline Reflections used in refinement & $288,428(28,313)$ & $203,960(20,185)$ & $163,135(16,107)$ & $32,664(1690)$ & $31,437(2534)$ \\
\hline$R_{\text {work }} / R_{\text {free }}$ & $0.17 / 0.19$ & $0.20 / 0.23$ & $0.23 / 0.26$ & $0.255 / 0.303$ & $0.21 / 0.25$ \\
\hline Protein residues & 1478 & 1478 & 3014 & 1484 & 703 \\
\hline RMS(bonds) & 0.015 & 0.020 & 0.012 & 0.007 & 0.007 \\
\hline RMS(angles) & 1.28 & 1.82 & 1.42 & 1.10 & 1.17 \\
\hline Ramachandran favored (\%) & 97 & 97 & 97 & 97 & 97 \\
\hline Ramachandran allowed (\%) & 2.5 & 2.5 & 3.1 & 2.9 & 2.3 \\
\hline Ramachandran outliers (\%) & 0.14 & 0.3 & 0.3 & 0.48 & 0.29 \\
\hline Rotamer outliers (\%) & 0.24 & 1.4 & 0.95 & 1.1 & 0.34 \\
\hline Clashscore & 3.73 & 1.63 & 1.02 & 3.42 & 2.64 \\
\hline Average B-factor & 15 & 21 & 15 & 32 & 44 \\
\hline Macromolecules & 14 & 20 & 14 & 34 & 43 \\
\hline Solvent & 27 & 31 & 43 & 37 & 38 \\
\hline
\end{tabular}

the S577A-25mer and D661A-25mer complexes. Table 1 shows the data collection and refinement statistics for all structures. The recognition tail adopts an identical distorted $3_{10}$ helix conformation inserted into the middle of the $\beta$-propeller domain in both the $25 \mathrm{mer}$ and $35 \mathrm{mer}$ complexes (Fig. 1f, g and 2). The carboxyl terminus sits in a pocket where it makes water-mediated hydrogen bonds to the protein. To our surprise, there are only a few hydrogen bonds between the protein and the tail (Fig. $2 \mathrm{c}$ for the S577A-25mer complex and Fig. 2d for the S577A-35mer complex). Comparison to the apo structure reveals that binding of substrate induces no significant changes in the core of the propeller domain ( $r m s d$ of $0.75 \AA$ over $360 \mathrm{C} \alpha$ positions for the S577A structures). The changes that occur (relative to the apo structure) are in loops around the catalytic site.

Significant differences between the two substrates are observed for the residues of the linker region, since it occupies distinct conformations on the $25 \mathrm{mer}$ and $35 \mathrm{mer}$ complexes (Fig. 2b). V24 faces Arg79 and V14 is toward Phe506. H23 does not form any hydrogen bonds, while H13 is hydrogen bonding with Glu601. Tyr494 is within hydrogen bonding distance from E22, while on the 25 mer complex Tyr494 is interacting with W9. This peptide twisting causes a tryptophan present in the peptides from both complexes (residue 19 in $35 \mathrm{mer}, 9$ in the $25 \mathrm{mer}$ ), C-terminal to the site of cleavage, to occupy a binding pocket close to the active site. The oxyanion-stabilizing Tyr496 is in close proximity to the core proline (P8) in the 25 mer structure (D661A mutant), while Tyr496 hydrogen bonds with P18 in the 35 mer complex (Fig. 2d).

Substrate residues I11-P18 (the core peptide is not seen in the 25mer, apart from weak density from P8 in the D661A-25mer complex) form a twisted loop, which makes contacts with the protein and within itself; atoms that will ultimately form the macrocycle are $7.6 \AA$ apart (Fig. $2 \mathrm{~d}$ ). The core peptide interposes between substrate P18 and enzyme Ser577, which is over $8 \AA$ away. Substrate P10, the site of proteolytic cleavage, is positioned for attack by Ser577 (the C $\beta$ of the mutated residue is $3.3 \AA$ from the carbonyl with plausible geometry). In the crystal structure of H698A-35mer complex, the hydroxyl of Ser577 is in hydrogen bonding distance from P10, in a position suited for nucleophilic attack but the structure is less ordered, notably the loop containing the mutation H698A. Tyr496 is on the opposite face of the carbonyl $2.8 \AA$ from the oxygen and positioned to stabilize the tetrahedral intermediate from attack of Ser577 (Fig. 2d). Both the interaction and the role of Tyr496 are conserved in other POPs. In the 35mer complex structures, residues 2-9 adopt a helical arrangement that ends up exposed to solvent at the $\mathrm{N}$ terminus and makes few contacts with the protein (Fig. 2d). In none of the GmPOPB structures that we have obtained are the catalytic residues arranged in the traditional manner, the closest approach of the His698 and Ser577 is $13 \AA$ and residues block simple movement (Supplementary Fig. 7). To confirm the importance of the putative catalytic triad for GmPOPB, the mutants S577A, D661A, and H698A were evaluated for activity, and were inactive with both $25 \mathrm{mer}$ and $35 \mathrm{mer}$ substrates, using $5 \mu \mathrm{M}$ GmPOPB and monitoring the reaction progress after $24 \mathrm{~h}$.

Mutations in the histidine loop decrease enzyme activity. To study other residues involved in hydrolysis and macrocyclization, additional mutants H698N, R663A, R663Q, R663K, and W6954 (deletion) were generated. These mutants were designed based on comparison of sequence alignments between other POP enzymes and the very similar POPA enzyme from G. marginata, enzymes that solely act as proteases. Arg663 is highly conserved in POPs and thought to play a role in catalysis or substrate binding, since it makes hydrogen bonds with the peptide substrate ${ }^{31}$. Supplementary Fig. 9a depicts a sequence alignment comparing POPA, POPB, PCY1 (another macrocyclase from the prolyl oligopeptidase family), and porcine POP while Supplementary Fig. 9b 
depicts the position of these residues in GmPOPB. H698N was insoluble and not evaluated. The other mutants possessed diminished activities for both peptide bond hydrolysis and macrocyclization. The amount of cyclic peptide present after incubation for $16 \mathrm{~h}$ with the $25 \mathrm{mer}$ substrate was R663Q $>$ R663A $>$ W695 $\Delta>$ R663K. When the 35mer was used as substrate, the mutants demonstrated diminished activity for peptide bond hydrolysis and almost undetectable activity for macrocyclization (Supplementary Fig. 9c).

Kinetic characterization and substrate scope of GmPOPB. Previous analysis employed GmPOPB isolated from the $G$. marginata mushroom after transformation with Agrobacterium tumefaciens ${ }^{15}$. We examined kinetic parameters and performed a substrate specificity study on the enzyme isolated employing a bacterial overexpression system. Substrates tested are shown in Supplementary Fig. 1. Our results on the native overexpressed enzyme confirm the previous findings ${ }^{15}$ obtained for protein purified from mushroom that the full-length $35 \mathrm{mer}$ substrate is cleaved and the resulting $25 \mathrm{mer}$ is released (Supplementary Fig. 3). The kinetic data for expressed protein with the $25 \mathrm{mer}$ but not 35 mer have been previously reported ${ }^{15,}{ }^{21}$. The 25 mer then rebinds (in competition with the $35 \mathrm{mer}$ ) for macrocyclization. Cleavage and macrocyclization do not occur in a single binding event ${ }^{15}$. The $25 \mathrm{mer}$ accumulates as an intermediate although the proteolysis reaction is slower than cyclic peptide formation (Supplementary Fig. 2). Very similar values for $K_{\mathrm{m}}$ and $k_{\text {cat }}$ were obtained for all full-length substrates evaluated, with $K_{\mathrm{m}}$ values ranging from 8 to $51 \mu \mathrm{M}$, while $k_{\text {cat }}$ was between 3.2 and $35 \mathrm{~min}^{-1}$ (Supplementary Fig. 2; Supplementary Table 2). Conservative amino-acid substitutions within the peptide substrate had no a

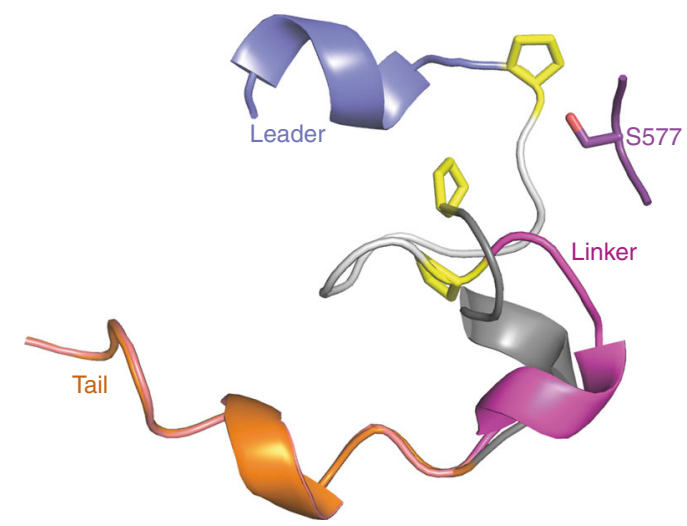

b

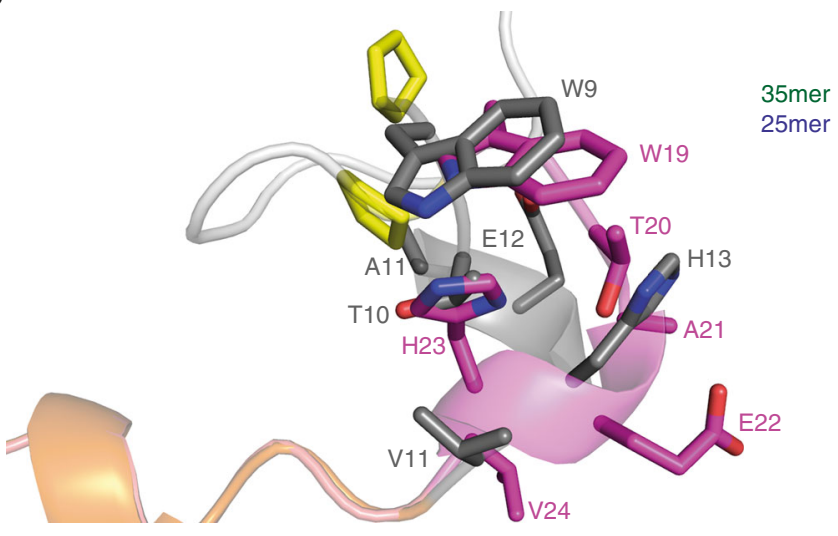

C
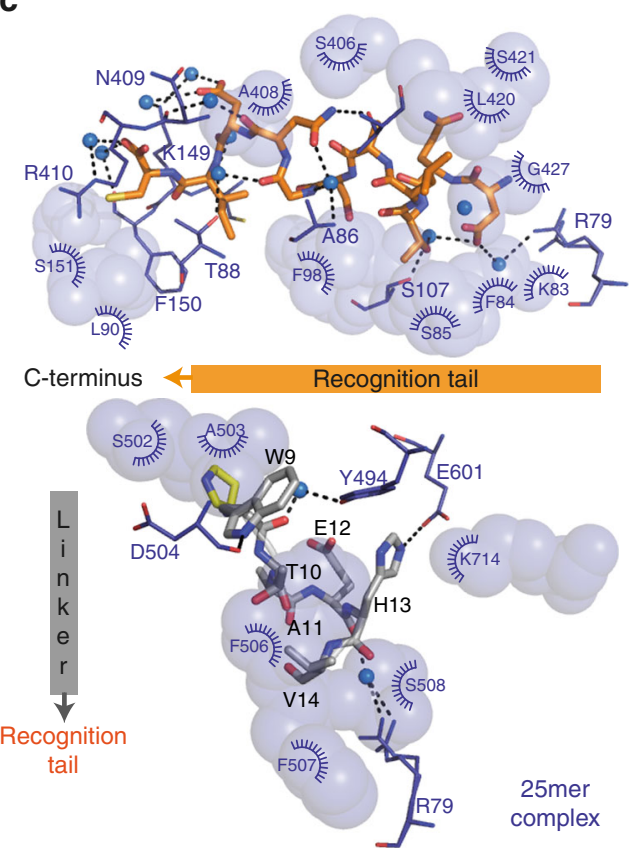

d
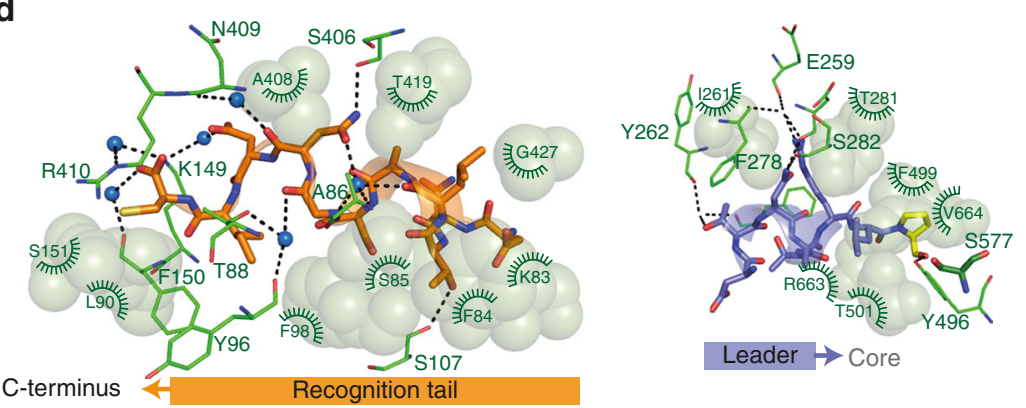

Leader $\rightarrow$ Core
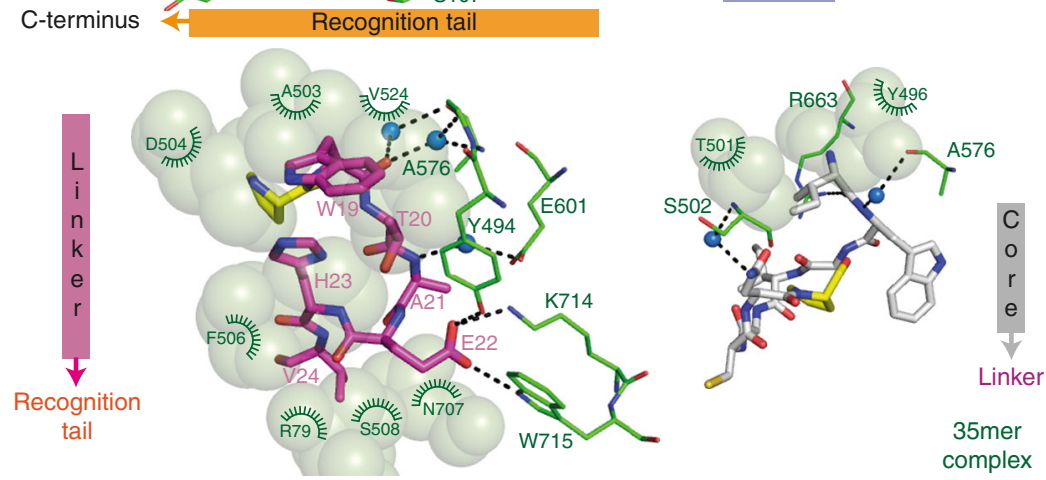

Fig. 2 Interactions between GmPOPB and linker regions for 35mer and 25mer substrates are different. a Overview of bound peptides. Colors for distinct peptide regions are as in Fig. 1b, except that the linker in the $25 \mathrm{mer}$ complex is in dark gray. Position of the catalytic Ser577, and core and leader proline residues (yellow) are indicated in sticks. b Comparison of the linker region between $35 \mathrm{mer}$ (magenta) and 25mer (gray) complexes. Highlighted are the very different position of Glu and His in contrast to tryptophan, which in both structures occupies the same pocket although the conformation is different. c Interactions between peptide tail and linker of the 25mer peptide and GmPOPB-S577A. Residues within hydrogen bonding distance are shown in lines, residues participating in hydrophobic interactions are in spheres, water molecules are depicted as small red spheres, prolines are shown in yellow. Color coding for peptide substrate regions follows a, residues from GmPOPB are depicted in blue. $\mathbf{d}$ Interactions between peptide tail, linker, core, and leader (anti-clockwise) of the 35mer peptide and GmPOPB-S577A. The same representation as c is used except residues from GmPOPB are depicted in green 

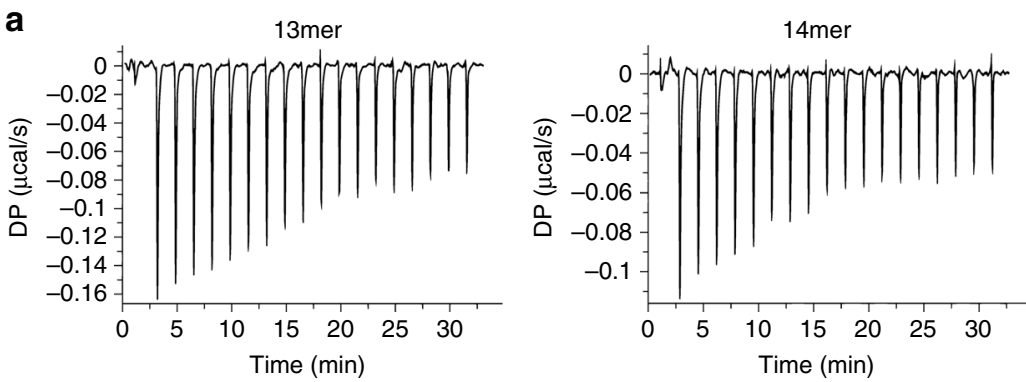

b
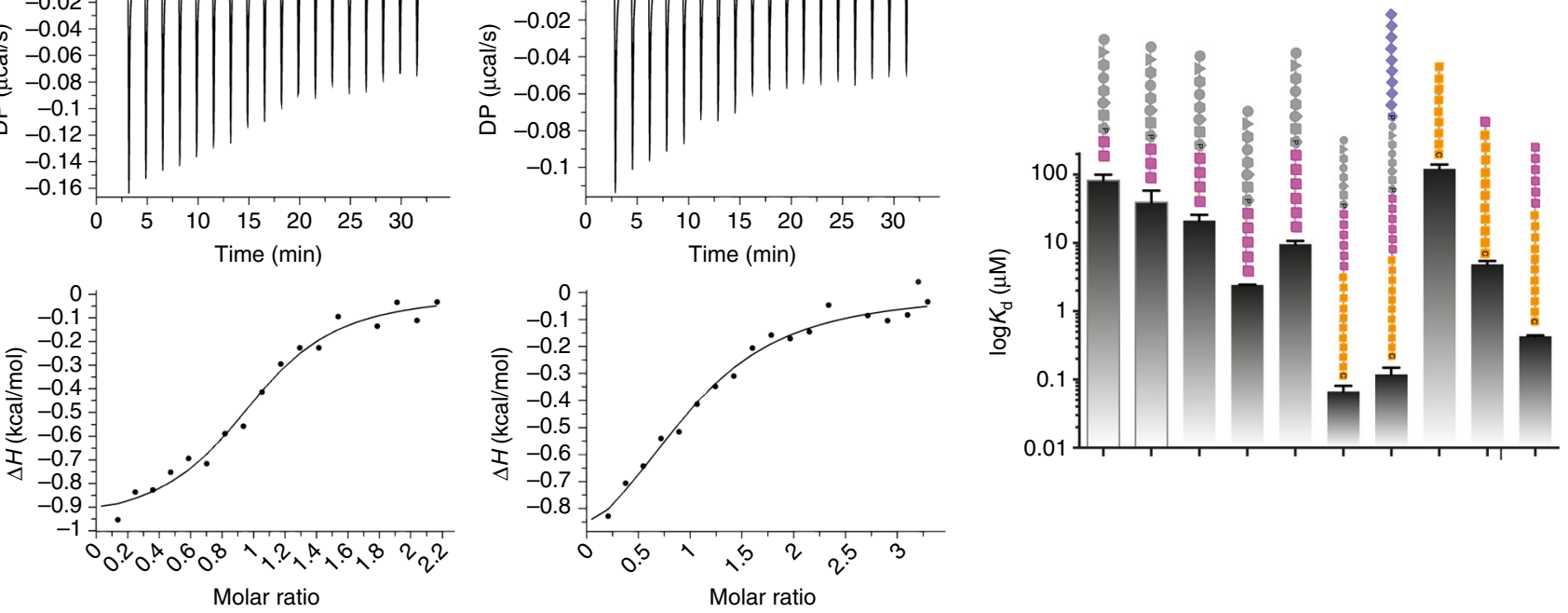

C

d

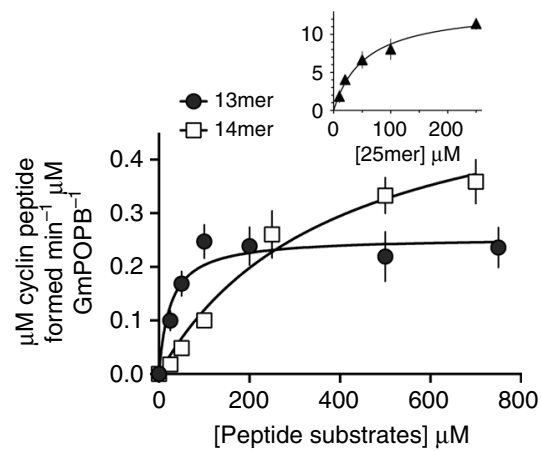

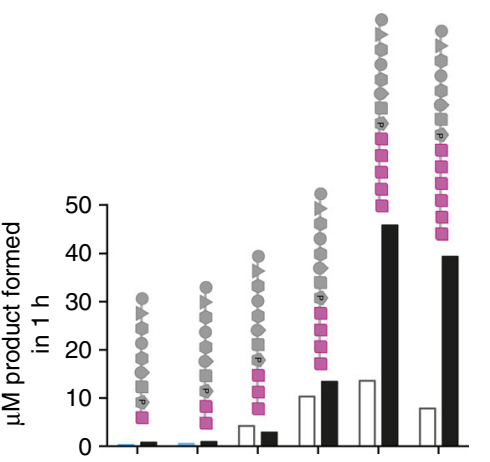

e

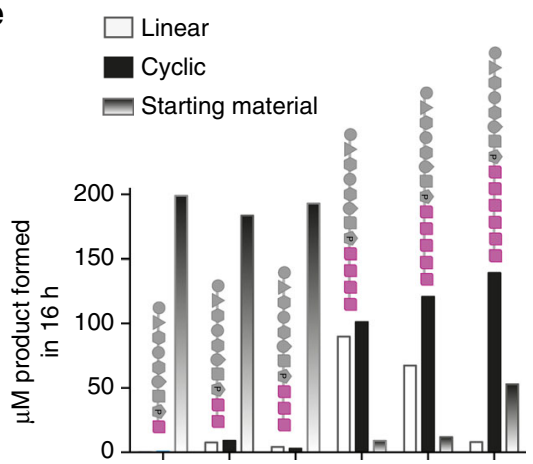

Fig. 3 Binding and kinetics of substrates and recognition tail truncations. a ITC binding curves for the 25mer peptide (obtained with the S577A mutant) and the 17 amino-acid recognition (linker and tail) sequence. $\mathbf{b} K_{d}$ values of peptides examined by ITC shows the 35 mer and 25 mer bind with similar affinity, the leader does not bind, the tail on its own binds weakly and the contributes to binding energy. The peptides are colored as Fig. 1c with $\mathrm{N}$-terminus at top. Error bars are standard error of the mean from the average of at least two independent measurements (Supplementary Table 3). c Michaelis-Menten curves show both the $13 \mathrm{mer}$ and $14 \mathrm{mer}$ are substrates for the enzyme. Fitted values for $K_{\mathrm{d}} K_{\mathrm{m}}$ and $k_{\text {cat }}$ are shown in Supplementary Tables 2 and 3 . Error bars are standard error of the mean from duplicate measurements. $\mathbf{d}$ Cyclic peptide produced after $1 \mathrm{~h}$ reaction with $1 \mu \mathrm{M} \mathrm{GmPOPB}$ and $200 \mu \mathrm{M}$ of various peptide substrates. e Peptide produced after $16 \mathrm{~h}$ of reaction with $1 \mu \mathrm{M} \mathrm{GmPOPB}$ and $200 \mu \mathrm{M}$ of various peptide substrates. Peptide sequences are colored as Fig. $1 \mathrm{~b}$ and detailed in Supplementary Fig. 1

effect either on kinetic parameters or yield of cyclic product. Less conservative substitutions such as mutation to alanine or 9 mer core (IWGIGCANP the bold underlined residue represents the insertion) led to reduced macrocyclization and increased linear peptide, the product of peptide hydrolysis instead of macrocyclization (Supplementary Fig. 8).

Equilibrium binding of substrates and products. Binding of the inactive mutant S577A to the $25 \mathrm{mer}$, 35mer, a series of truncated substrates (10mer-14mer), as well as the recognition sequence (17mer) WTAEHVDQTLASGNDIC, the truncated recognition sequences VDQTLASGNDIC and TLASGNDIC, and the leader peptide MFDTNATRLP were evaluated by isothermal titration calorimetry (ITC). The results of S577A with both the $25 \mathrm{mer}$ and recognition sequence have previously been reported ${ }^{21}$. Binding of H698A to the $25 \mathrm{mer}$ was also measured. The only peptide showing no detectable binding at concentrations up to $1 \mathrm{mM}$ was the 10 -residue leader peptide MFDTNATRLP. The full-length substrates and products displayed tight binding
$\left(K_{\mathrm{d}-25 \mathrm{mer}-\mathrm{S} 577 \mathrm{~A}}=67 \pm 14 \mathrm{nM}^{21}, \quad K_{\mathrm{d}-25 \mathrm{mer}-\mathrm{H} 698 \mathrm{~A}}=47 \pm 11 \mathrm{nM}\right.$ $K_{\mathrm{d}-35 \mathrm{mer}}=120 \pm 30 \mathrm{nM}, K_{\mathrm{d} \text {-recognition }}=430 \pm 10 \mathrm{nM}^{21}$; binding is dominated by enthalpic contributions (Supplementary Fig. 6b) (Fig. 3a shows representative ITC traces for the 13 mer and $14 \mathrm{mer}$ substrates, Fig. $3 \mathrm{~b}$ shows $K_{\mathrm{d}}$ values for all peptides evaluated, Supplementary Fig. 10 shows raw data for all binding curves). The inactive mutant $\mathrm{H} 698 \mathrm{~A}$ has identical $K_{\mathrm{d}-25 \text { mer }}$ to the S577A mutant suggesting the lack of activity results from catalytic incompetence rather than disruption of substrate binding. Interestingly, despite being longer and having the potential for more interactions with the protein, the $35 \mathrm{mer}$ peptide shows slightly weaker binding compared to the $25 \mathrm{mer}$, mostly due to decreased $\Delta H$. A comparison of the complex structures shows that in the 35 mer complex there is disorder of side chains in the segment TAEHVD (linker region) but not in the $25 \mathrm{mer}$. To investigate the role of recognition tag peptides corresponding to the entire recognition sequence (linker plus tail, WTAEHVDQTLASGNDIC-17 residues), the recognition tail plus the valine from the linker (VDQTLASGNDIC 12 residues) and the highly conserved portion of the tail (TLASGNDIC 9 residues) were 
a

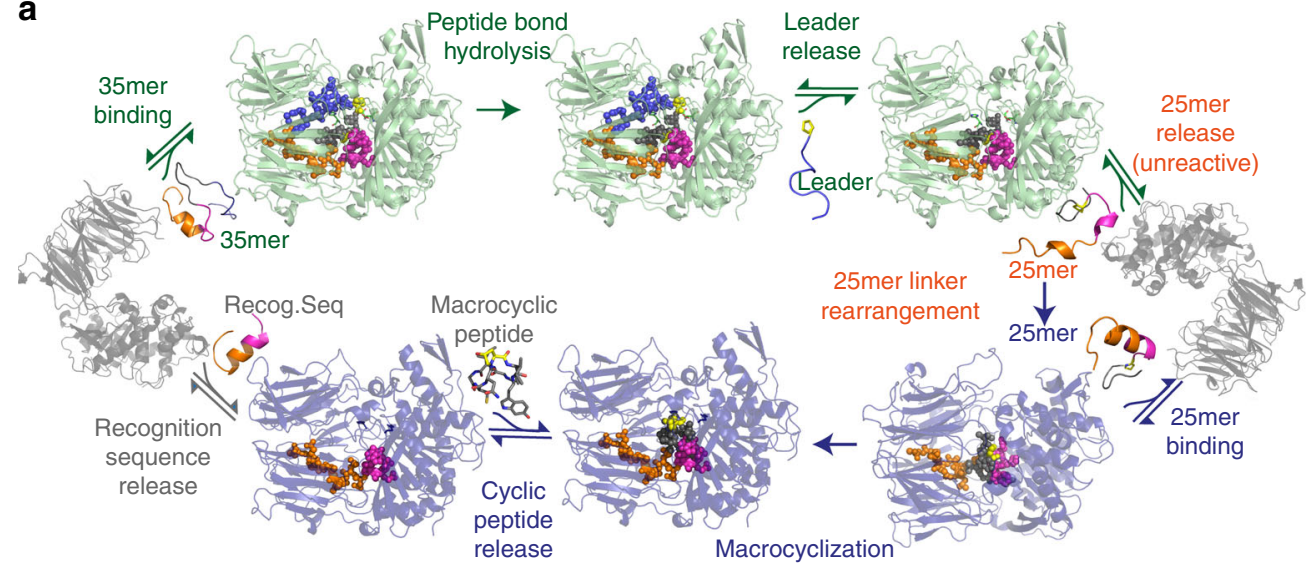

b

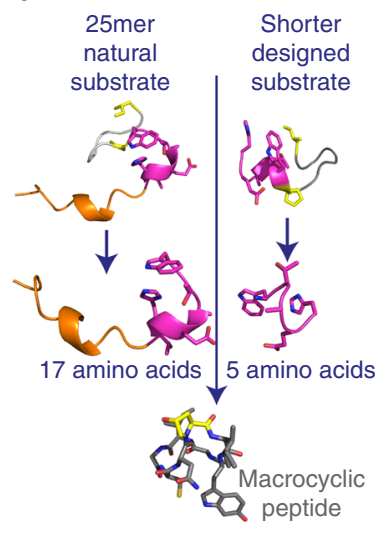

Fig. $4 \mathrm{GmPOPB}$ catalyzes peptide bond hydrolysis and macrocyclization. a The sequence of events catalyzed by GmPOPB starting with the 35mer peptide substrate. Peptide bond hydrolysis yields the leader sequence (which dissociates) and the 25 mer peptide. The enzyme-bound $25 \mathrm{mer}$ is conformationally trapped and macrocyclization cannot proceed. The $25 \mathrm{mer}$ must dissociate to rearrange and re-bind only then does macrocyclization occur. Apo enzyme is shown in gray, the enzyme functioning as a protease is colored green, and functioning as a macrocyclase in blue. The peptide is colored as Fig. $1 \mathrm{~b}$. $\mathbf{b}$ A $25 \mathrm{mer}$ substrate yields a 17 amino-acid by-product, whereas the 13mer substrate generates a 5 amino-acid by-product, a much more economically efficient reaction. Substrates are colored as Fig. 1b

tested for binding and gave $K_{\mathrm{d}-17 \text { mer-recogseq }}=0.43 \pm 0.01 \mu \mathrm{M}^{21}$, $K_{\mathrm{d}-12 \mathrm{mer}-\text { recogSeq }}=5 \pm 1 \mu \mathrm{M}$ and $K_{\mathrm{d}-9 \text { mer-recogseq }}=121 \pm 19 \mu \mathrm{M}$ (Supplementary Table 3; Supplementary Figs. 6 and 10). Previously, we showed that the recognition sequence dominates binding, with a difference in $\Delta G$ of only $1.34 \mathrm{kcal} \mathrm{mol}^{-1}$ between the $17 \mathrm{mer}$ recognition sequence and the $25 \mathrm{mer}$ peptide ${ }^{21}$. To explore how much contribution to the binding energy comes from the linker region, we evaluated the binding of truncated recognition sequences. Our data show that the linker region is important in binding as the loss of the linker (shrinking the recognition sequence from 17 to 12 amino acids) reduces binding affinity 20 -fold. On its own, the highly conserved nine-residue tail bound rather weakly, consistent with the few interactions observed with the protein. Following from this finding, a series of truncated peptides (core plus parts of the linker) were tested and revealed a trend in which binding affinity increased from 10mer to 13 mer $\left(K_{\mathrm{d}-10 \mathrm{mer}}=83 \pm 17 \mu \mathrm{M}, K_{\mathrm{d}-11 \mathrm{mer}}=39 \pm 18 \mu \mathrm{M}, K_{\mathrm{d}-12 \mathrm{mer}}=21\right.$ $\left.\pm 5 \mu \mathrm{M}, K_{\mathrm{d}-13 \mathrm{mer}}=2.4 \pm 0.1 \mu \mathrm{M}\right)$ peptides, but decreased slightly with the 14 mer peptide $\left(K_{\mathrm{d}-14 \mathrm{mer}}=9.5 \pm 1.1 \mu \mathrm{M}\right)$ (Fig. $3 \mathrm{~b}$ ); the 9 mer was not sufficiently soluble for analysis. We noted that the difference in affinity between the $35 \mathrm{mer}$ and the core plus linker (13mer) was $\sim 20$-fold.

\section{Discussion}

GmPOPB can form and hydrolyze peptide bonds depending on the substrate length and structure. Both reactions proceed by similar chemical mechanisms, passing through an acyl enzyme intermediate. Typical POPs catalyze peptide bond cleavage following a proline, and less efficiently an alanine, showing strong preference for substrates shorter than 30 amino acids $^{32}$. GmPOPB is unusual in that it processes a 35 amino-acid substrate, the longest observed for a POP. POP enzymes possess an aspartate, histidine, and serine catalytic triad. Molecular dynamic simulation studies comparing the porcine and bacterial POPs have proposed a mechanism in which inter-domain "breathing" is required for catalysis ${ }^{33}$. Although structures of apo and POPs bound to short peptide substrates and inhibitors (ranging from $2^{30}$ to 7 amino acids ${ }^{34}$ ) are available, no substrate complex with a long peptide has previously been determined. Interestingly, in GmPOPB complexes the residues of the presumed catalytic triad are not aligned. His698 is $12 \AA$ away (much further than in any other POP, Supplementary Fig. 7) from Ser577 but is essential for catalysis rather than binding. The enzyme-substrate complex shows that, apart from His698, there is no other residue in proximity to the active site capable of acting as general acid/ general base with $\mathrm{p} K_{\mathrm{a}}$ values near to the 8.0 measured from kinetic analysis ${ }^{21}$. The domain breathing motion similar to, but larger than, other POPs could correctly position the His698. Mutations of the highly conserved Arg663 and deletion of Trp695 (an insertion relative to other POPs, Supplementary Fig. 9a), which we predicted would affect loop structure and dynamics, were severely compromised in activity with both $25 \mathrm{mer}$ and 35 mer substrates, consistent with our prediction. We cannot, however, exclude the possibility that His698 may be required for positioning toward a productive conformation of the enzyme-substrate complex rather than act as a base per se. The histidine loop is disordered on the H698A mutant structure and the H698N mutant is insoluble, hinting at a stabilizing role for His698. Analogous to lipid acyl hydrolases ${ }^{35}$, the enzyme would function with a catalytic dyad in which Ser577 is activated by a water molecule bridged to Asp661.

Comparison of the three-dimensional structures of the enzyme in complex with $25 \mathrm{mer}$ and $35 \mathrm{mer}$ substrates reveals only minor rearrangements of the protein, mostly in loops that accommodate the longer substrate. Both $35 \mathrm{mer}$ (proteolysis) and 25 mer (macrocyclization) substrates bind to GmPOPB with high affinity driven mainly by enthalpy (Fig. 3b, Supplementary Fig. 7; Supplementary Table 3). Consistent with the observation of similar binding affinities of the $25 \mathrm{mer}$ and $35 \mathrm{mer}\left(K_{\mathrm{d}} 67\right.$ and $120 \mathrm{nM}$, respectively) ${ }^{21}$, the 10 -residue leader (only present in $35 \mathrm{mer}$ ) does not bind. In both the $25 \mathrm{mer}$ and $35 \mathrm{mer}$ complex structures, the recognition tail (C-terminal 11 residues) is embedded deeply into the $\beta$-propeller domain in an essentially identical arrangement. The linker region, however, adopts very different arrangements in the two complexes, thus its interactions with the protein are quite distinct in the two structures (Fig. 2). ITC measurements show that the linker region, particularly the portion following the core peptide, makes substantial contribution to the binding energy. This is in contrast to the heterocyclase class of RIPP enzymes, where the linker plays no role and can be varied ${ }^{36}$. Our data show that the structure of the linker is important in binding and determines the orientation of the substrate at the active site (thus its fate). 
Previous kinetic assays and ours reveal that after removal of the leader, the remaining $25 \mathrm{mer}$ is released from GmPOPB, then it rebinds and undergoes the macrocyclization reaction ${ }^{15}$. In the 35 mer complex, the core and linker adopt a tightly packed arrangement that is wedged between the active site loops. We conclude that the linker and/or core are unable to refold to the conformational arrangement seen in the $25 \mathrm{mer}$ complex (required for macrocyclization) in situ on a timescale comparable to dissociation. We propose the arrangement of and interactions between C-terminal 25 residues and protein that are seen in the 35 mer complex act as a kinetic trap, which can only be escaped by dissociation (Fig. 4a). Conformationally trapped peptide reaction intermediates have been identified in other systems. For example, inhibition of proteases by serpins is accomplished by a suicide substrate mechanism, in which the complex is trapped in an inactive arrangement ${ }^{37}$.

Having identified the key role of the linker, we predicted that it should be possible to design simpler macrocyclization substrates that lacked the recognition tail. This would be valuable since the use of 25 mer substrates to make eight residue macrocycles is not economic. ITC shows a 10 -fold reduction in binding from $35 \mathrm{mer}$ to 13 mer, kinetic analysis reveals the 13 mer substrate has a $K_{\mathrm{m}}$ $(25 \mu \mathrm{M})$ within error to the $25 \mathrm{mer}$ substrate $(50 \mu \mathrm{M})$, while the $14 \mathrm{mer}$ possesses higher $K_{\mathrm{m}}(380 \mu \mathrm{M})$. Similar $k_{\text {cat }}$ values were observed with both shorter substrates $\left(0.49\right.$ and $0.58 \mathrm{~min}^{-1}$ for the $13 \mathrm{mer}$ and $14 \mathrm{mer}$, respectively, Fig. 3c; Supplementary Table 2) but these are smaller than the $25 \mathrm{mer}\left(18 \mathrm{~min}^{-1}\right)$. Linear peptide (product of hydrolysis instead of macrocyclization) was observed when shorter peptides were utilized as substrates (Fig. 3d) consistent with the linker playing a key role in substrate positioning. After $16 \mathrm{~h}$ of reaction both $13 \mathrm{mer}$ and $14 \mathrm{mer}$ substrates produce similar amounts of macrocycle, but the $14 \mathrm{mer}$ generates less linear product. Linear peptide produced this may not be a significant drawback, as purification of macrocycles from liner peptides is straightforward ${ }^{12,38}$. Compared to PatG this represents a significant improvement, since biocatalytic reactions with PatG in vitro can require over 7 days and utilize up to stoichiometric amounts enzyme ${ }^{12,38}$.

GmPOPB is an unusual enzyme catalyzing, depending on substrate length, proteolysis, or macrocyclization using the same catalytic machinery (Fig. 4a). Further complexity comes from the fact that GmPOPB itself generates its 25 residue macrocyclization substrate. The internal structure of the substrate is critical to how the enzyme binds the substrate and to which reaction is catalyzed. As a consequence of this requirement for a specific substrate structure, the enzyme must release the 25 mer peptide, allowing it to refold rather than simply moving to the second reaction in a processive manner. Previous work had identified the crucial nature of the recognition sequence in the substrate, but suggested its full length was a requirement for macrocyclization. Our structural work supported by calorimetry and kinetics reveals that shorter peptides are suitable substrates, if their design preserves important interactions with the protein and maintains the peptide structural recognition. GmPOPB recognizes residues within the linker connecting the core and the recognition tail, and this recognition is critical to position the substrate for macrocyclization. A substrate with five or six C-terminal residues (as opposed to 17) chosen to mimic the linker can be efficiently macrocyclized at synthetically useful rates (Fig. 4b). This work highlights the power of structural and mechanistic studies to redesign substrates or enzymes for use in biotechnology.

Note added in proof: Since the submission of this manuscript two papers were published studying POPs, further demonstrating the importance of this class of macrocyclase enzymes. One reports the structure of the related PCY 1 enzyme ${ }^{55}$ and the other discusses broadening of the substrate profile of $\mathrm{GmPOPB}^{56}$.

\section{Methods}

Materials. Peptides were purchased from Biosynthesis, as free amine and free carboxylic acids, at a purity $>90 \%$. Buffers and chemicals, unless specified, were from Sigma.

Expression of recombinant proteins. The plasmid pJExpress 414 encoding the codon optimized G. marginata $P O P B$ gene was purchased from DNA 2.0. Plasmids were transformed into BL21(DE3) cells (Agilent). Cultures $(50 \mathrm{~mL})$ were grown overnight at $37^{\circ} \mathrm{C}$ in the presence of $100 \mu \mathrm{g} / \mathrm{mL}$ ampicillin, then diluted 100 -fold into $6 \mathrm{~L}$ Terrific Broth (TB) media. These cultures were grown at $37^{\circ} \mathrm{C}$ with shaking $(200 \mathrm{rpm})$ until the optical density at $600 \mathrm{~nm}$ (OD600) reached 0.6. Cells were cooled down for $1 \mathrm{~h}$ to $16^{\circ} \mathrm{C}$, and protein expression was then induced by the addition of $0.5 \mathrm{mM}$ isopropyl $\beta$-D-thiogalactopyranoside (IPTG, Generon). Cultures were incubated for an additional $16 \mathrm{~h}$ and centrifuged at $6000 \times \mathrm{g}$ for $15 \mathrm{~min}$. Cell pellets were resuspended in $250 \mathrm{~mL} \mathrm{Ni-NTA} \mathrm{lysis/wash} \mathrm{buffer} \mathrm{A}$ (50 mM HEPES pH 8.0, $300 \mathrm{mM} \mathrm{NaCl}, 10 \mathrm{mM}$ imidazole, $10 \%$ glycerol, and $2 \mathrm{mM}$ $\beta$-mercaptoethanol) supplemented with complete EDTA-free protease inhibitor tablets (Roche Applied Science). The resulting suspension was lysed by two passages through a cell homogenizer at $30,000 \mathrm{psi}$, and purified by nickel chromatography. Each desired protein was eluted using a step elution with lysis buffer supplemented with $250 \mathrm{mM}$ imidazole (buffer B). Eluted protein was dialyzed overnight against buffer C (50 mM HEPES (pH 8.0), $50 \mathrm{mM} \mathrm{NaCl}, 10 \%$ glycerol, and $2 \mathrm{mM} \beta$-mercaptoethanol) while simultaneously the His-tag was cleaved by TEV protease (prepared in house ${ }^{39}$ ). This dialyzed TEV-cleaved mixture was loaded onto a Histrap column connected in tandem to a Hitrap Q-FF column. Both columns were washed with buffer $\mathrm{C}$, and GmPOPB was eluted during this wash. Fractions were pooled and concentrated to $<8 \mathrm{~mL}$ (at $10 \mathrm{mg} / \mathrm{mL}$ approximately). Protein was loaded onto a Superdex S200 gel filtration column (GE Healthcare) pre-equilibrated with storage buffer D (50 mM HEPES ( $\mathrm{pH} 8.0$ ), $50 \mathrm{mM} \mathrm{NaCl}, 10 \%$ glycerol, and $2 \mathrm{mM} \beta$-mercaptoethanol). Fractions containing pure protein were combined, concentrated, divided in aliquots, flash frozen, and stored at $-80^{\circ} \mathrm{C}$. Protein concentrations were determined by absorbance at $280 \mathrm{~nm}^{40}$.

Site-directed mutagenesis. Mutants S577A, D661A, H698N, R663A, R663Q, $\mathrm{R} 663 \mathrm{~K}$, and $\mathrm{W} 695 \Delta$ were generated by a published mutagenesis protocol ${ }^{41}$. Oligonucleotides for mutagenesis were purchased from IDT. Sequences of primers used for mutagenesis and sequencing are given in Supplementary Table 1. Sequencing was performed using at least three primers to cover the entire gene sequence (Eurofins).

General procedure for kinetic assays. Comparison between distinct substrates was performed in $50 \mathrm{mM}$ Tris $\mathrm{pH} 8.0,50 \mathrm{mM} \mathrm{NaCl}, 10 \mathrm{mM}$ DTT with varying concentrations of substrates at room temperature. All reactions were performed in duplicates. Reactions were started by adding GmPOPB (50 nM for GmAMA1_C6S, $1 \mu \mathrm{M}$ for the $13 \mathrm{mer}$ and $14 \mathrm{mer}$, and $20 \mathrm{nM}$ for other substrates) to the assay mixture containing buffer and peptide. Reactions were quenched at several time points by adding $50 \mu \mathrm{L}$ reaction mixture to $20 \mu \mathrm{L} 6 \%$ TFA. Reactants were separated from products for quantification by injecting $50 \mu \mathrm{L}$ of each quenched time point mix onto a ZORBAX SB-C18, $5 \mu \mathrm{m}, 9.4 \times 50 \mathrm{~mm}$ (Agilent) column connected to an Agilent LC-MS (G6130B Single Quad, Agilent Technologies). Reactants were separated from products using a gradient from $\mathrm{H}_{2} \mathrm{O}$ containing $0.1 \%$ TFA or $0.1 \%$ formic acid and $5 \%$ acetonitrile to $50 \%$ acetonitrile,

at $1.5 \mathrm{ml} / \mathrm{min}$ for $8 \mathrm{~min}$. Peaks with ultra violet (UV) absorbance at 220 and $280 \mathrm{~nm}$ were integrated, the area of peaks corresponding to reactant and products was used to calculate the percentage of product formed after a correction for differences in the extinction coefficient of each peptide was applied $\left(\varepsilon_{280-25 \mathrm{mer}}=\right.$ $11,000 \mathrm{M}^{-1} \mathrm{~cm}^{-1}, \varepsilon_{220-25 \mathrm{mer}}=46,000 \mathrm{M}^{-1} \mathrm{~cm}^{-1}, \varepsilon_{280-\text { cyclic }}=5500 \mathrm{M}^{-1} \mathrm{~cm}^{-1}$, $\varepsilon_{220-\text { cyclic }}=34,000 \mathrm{M}^{-1} \mathrm{~cm}^{-1}$, and $\left.\varepsilon_{280 \text {-tail }}=5500 \mathrm{M}^{-1} \mathrm{~cm}^{-1}\right)$. The sum of product + substrate was assumed equal to the total initial amount of substrate, product converted from $\%$ to concentration. This value was divided by concentration of enzyme present to yield $v / E_{\mathrm{t}}\left(\mathrm{min}^{-1}\right)$. When enzyme mutants and peptides containing alanine in the core sequence were tested for activity, higher concentrations $5 \mu \mathrm{M}$ enzyme and $100 \mu \mathrm{M}$ substrate were incubated for 1 and $18 \mathrm{~h}$ at room temperature. For progress curves with the 35 mer substrate, measurements were triplicate and quantification relied on ion counts from mass spectrometry. Mass signals corresponding to $35 \mathrm{mer}(1282.9 \mathrm{Da}-\mathrm{M}+3 \mathrm{H})$, 25mer (900.7 Da-M+2H), leader peptide $(1165.5 \mathrm{Da}-\mathrm{M}+\mathrm{H})$, recognition sequence $(930.4 \mathrm{Da}-\mathrm{M}+2 \mathrm{H})$, cyclic peptide $(841.3 \mathrm{Da}-\mathrm{M}+\mathrm{H})$, linear peptide $(859.4 \mathrm{Da}-\mathrm{M}+\mathrm{H})$ were monitored, the area of each was integrated and quantified using a calibration curve performed with the $25 \mathrm{mer}, 35 \mathrm{mer}$, cyclic, and linear peptides as standards. Authentic cyclic peptide was quantified by UV absorbance. Data showing products formed after 1 and $16 \mathrm{~h}$ with truncated peptides were performed twice. UV and ion count approaches gave similar results for the $25 \mathrm{mer}$. Kinetic data were fitted to a Michaelis-Menten equation using GraphPad Prism, and values reported are average and standard error of the mean.

Isothermal titration calorimetry. All titrations were performed on a MicroCal PEAQ-ITC instrument (MicroCal, Malvern Instruments, Northamption, MA, USA) and the results were fitted with PEAQ-ITC analysis software (MicroCal, 
Malvern Instruments, Northampton, MA, USA). Peptide ligand solutions were prepared in $20 \mathrm{mM}$ Tris $\mathrm{pH} 8.0$ containing $1 \mathrm{mM}$ DTT, prior to buffer exchange by three cycles of dilution in $50 \mathrm{mM}$ Tris $\mathrm{pH} 8.0$ with $50 \mathrm{mM} \mathrm{NaCl}, 10 \mathrm{mM}$ DTT followed by concentration using a Microsep Advance centrifugal device equipped with a $1 \mathrm{kDa}$ cut off membrane (Pall Corporation). The same three cycles of dilution in $50 \mathrm{mM}$ Tris $\mathrm{pH} 8.0$ with $50 \mathrm{mM} \mathrm{NaCl}$ and $10 \mathrm{mM}$ DTT followed by concentration were performed with the protein to be used in the titration using a Vivaspin protein concentrator spin column with a $30 \mathrm{kDa}$ cut off (GE Healthcare). A final dilution to the concentration to be used for titration was performed using the buffer that passed through during the protein buffer exchange, both for the protein and peptide to be used to avoid any possible buffer mismatch. The stirred cell contained $300 \mu \mathrm{L}$ of protein (the inactive mutant GmPOPB_S577A at $20 \mu \mathrm{M}$ for $35 \mathrm{mer}, 36 \mu \mathrm{M}$ for $10 \mathrm{mer}, 36 \mu \mathrm{M}$ for $11 \mathrm{mer}, 29 \mu \mathrm{M}$ for $12 \mathrm{mer}, 42 \mu \mathrm{M}$ for $13 \mathrm{mer}$, $29 \mu \mathrm{M}$ for $14 \mathrm{mer}, 37 \mu \mathrm{M}$ for $9 \mathrm{mer}$ recognition sequence, $21 \mu \mathrm{M}$ for $12 \mathrm{mer}$ recognition sequence), and the injection syringe contained $75 \mu \mathrm{L}$ of peptide ligand $(200$ $\mu \mathrm{M}$ for $35 \mathrm{mer}, 924 \mu \mathrm{M}$ for $10 \mathrm{mer}, 761 \mu \mathrm{M}$ for $11 \mathrm{mer}, 484 \mu \mathrm{M}$ for $12 \mathrm{mer}, 442 \mu \mathrm{M}$ for $13 \mathrm{mer}, 582 \mu \mathrm{M}$ for $14 \mathrm{mer}, 1 \mathrm{mM}$ for 9 mer recognition sequence, $677 \mu \mathrm{M}$ for $12 \mathrm{mer}$ recognition sequence). Titrations of peptide into protein solutions were conducted at $20^{\circ} \mathrm{C}$. For all the titration experiments, a total of 19 injections of $2 \mu \mathrm{L}$ were made at $120 \mathrm{~s}$ intervals. The heat released due to the first injection $(0.4 \mu \mathrm{L})$ was excluded from data analyses. Binding data with the H698A mutant were performed by titrating enzyme $(319 \mu \mathrm{M}$ stock) into 25 mer peptide $(27 \mu \mathrm{M})$. Blank runs in which peptide (or H698A) was titrated into buffer were performed to correct for the heats of dilution and mixing, and the dilution isotherm for each peptide ligand was subtracted from the respective binding isotherm prior to curve fitting. Equilibrium dissociation constants $\left(K_{\mathrm{d}}\right)$ as well as $\Delta H$ and $\Delta S$ values for binding of each peptide to protein were obtained by fitting the calorimetric data with a single-site model using the stoichiometry parameter $n$ fixed at 1.0 using Malvern PEAQ-ITC data analysis software. The ITC data for S577A with both the $25 \mathrm{mer}$ and recognition sequence $(17 \mathrm{mer})$ have previously been published ${ }^{21}$. We performed all ITC binding experiments at least in duplicate, and calculations of average and standard error of the mean were performed with GraphPad Prism.

Structural biology. ApoGmPOPB crystals were obtained by vapor diffusion at $20{ }^{\circ} \mathrm{C}$ using the hanging drop method. The initial conditions in the drop were $100 \mathrm{mg} / \mathrm{mL}$ GmPOPB, 30\% PEG4000, and $100 \mathrm{mM}$ MES buffer, pH 6.5. Several crystal clusters appeared after incubation at $20^{\circ} \mathrm{C}$ for 1 week, which were crushed and used for microseeding using a $80 \mathrm{mg} / \mathrm{mL}$ GmPOPB solution and the same precipitant. Crystals were cryoprotected by addition of $10 \%$ glycerol to precipitant solution, and flash cooled in liquid nitrogen. All complex structures were obtained by vapor diffusion at $20^{\circ} \mathrm{C}$ using the sitting drop method. Complexes with both $25 \mathrm{mer}$ and $35 \mathrm{mer}$ peptides were obtained by co-crystallization of $100 \mathrm{mg} / \mathrm{ml}$ protein and two-fold molar excess of peptide, and contained $12.5 \mathrm{mM}$ Hexammine cobalt chloride as additive. For the S577A-25mer complex, crystals were obtained with $28 \%$ PEG6000, $100 \mathrm{mM}$ Bicine $\mathrm{pH} 9.0,60 \mathrm{mM}$ magnesium formate, and $2.42 \%$ DMSO. Crystals were cryoprotected by addition of $12 \%$ glycerol to precipitant solution, and flash cooled in liquid nitrogen. For the D661A-25mer complex, crystals were obtained with $28 \%$ PEG6000, $100 \mathrm{mM}$ Tris pH 8.3, and $90 \mathrm{mM}$ sodium/potassium phosphate. Crystals were cryoprotected by the addition of $12 \%$ glycerol to precipitant solution, and flash cooled in liquid nitrogen. Crystals of S577A-35mer complex were obtained with $28 \%$ PEG6000, $100 \mathrm{mM}$ Bicine $\mathrm{pH}$ 8.7, $64 \mathrm{mM}$ sodium potassium phosphate. Crystals were cryoprotected by addition of $12 \%$ glycerol to precipitant solution, and flash cooled in liquid nitrogen. For the H698A-25mer complex, crystals were obtained with 27\% PEGMME2000, $90 \mathrm{mM}$ Bicine $\mathrm{pH} 8.7$, and $100 \mathrm{mM}$ potassium thiocyanate. Crystals were cryoprotected by addition of $13 \%$ glycerol to precipitant solution, and flash cooled in liquid nitrogen.

Data were collected at $100 \mathrm{~K}$ at the European Synchrotron Radiation Facility (ESRF) beamline ID30A-3 (S577A-25mer complex), Diamond Light Source beamlines I02 (apo GmPOPB), I04-1 (S577A-35mer complex), I03

(D661A-25mer), or in house on a Rigaku 007HFM rotating anode X-ray generator with a Saturn 944 CCD detector (H698A-35mer). Data were processed with HKL2000 ${ }^{42}$ (S577A-25mer and H698A-35mer complexes) or Xia2-DIALS ${ }^{43}$ (apo GmPOPB, S577A-35mer and D661A-25mer complexes). All structures were solved by molecular replacement with PHASER ${ }^{44}$, followed by density improvement using PARROT ${ }^{45}$, then automatic building using Buccaneer ${ }^{46}$ and Arp/wARP ${ }^{47}$. Manual rebuilding was performed with $\mathrm{COOT}^{48}$, and refinement was performed with REFMAC $5^{49}$ implemented in the CCP4 program suite ${ }^{50}$, Phenix ${ }^{51}$, and PDB_REDO ${ }^{52}$. Structural figures were generated with PyMOL (DeLano Scientific, LLC). In Fig. 4 the solution structures for 13mer, 25mer, and $35 \mathrm{mer}$ free were generated by PEPFOLD ${ }^{53,54}$ and the macrocyclic peptide was adapted from $\alpha$-amanitin (PDB: 3CQZ).

Data availability. Sequences and plasmids for all clones used in this study have been deposited on Addgene, with the following IDs: 92234 (GmPOPB-Wild type), 92235 (GmPOPB-S577A). 92236 (GmPOPB D661A), 92237 (GmPOPB-H698A), 92238 (GmPOPB-R663A), 92239 (GmPOPB-R663K), 92240 (GmPOPB-R663Q), 92241 (GmPOPB-W695 1 ), and 92242 (GmPOPB-H698N). Coordinates have been deposited in the Protein Data Bank, with accession codes 5N4B (S577A mutant bound to 25 mer peptide), $5 \mathrm{~N} 4 \mathrm{C}$ (S577A mutant bound to 35 mer peptide), $5 \mathrm{~N} 4 \mathrm{D}$ (D661A mutant bound to 25mer peptide), 5N4E (H698A mutant bound to $35 \mathrm{mer}$ peptide), and $5 \mathrm{~N} 4 \mathrm{~F}$ (apoGmPOPB). All the other data supporting the findings of this study are provided within the article and supplementary files, and available from the corresponding author upon reasonable request.

Received: 21 February 2017 Accepted: 2 August 2017

Published online: 19 October 2017

\section{References}

1. Driggers, E. M., Hale, S. P., Lee, J. \& Terrett, N. K. The exploration of macrocycles for drug discovery-an underexploited structural class. Nat. Rev. Drug Discov. 7, 608-624 (2008).

2. Craik, D. J. Chemistry. Seamless proteins tie up their loose ends. Science 311, 1563-1564 (2006).

3. Hewitt, W. M. et al. Cell-permeable cyclic peptides from synthetic libraries inspired by natural products. J. Am. Chem. Soc. 137, 715-721 (2015).

4. Arnison, P. G. et al. Ribosomally synthesized and post-translationally modified peptide natural products: overview and recommendations for a universal nomenclature. Nat. Prod. Rep. 30, 108-160 (2013).

5. Ortega, M. A. \& van der Donk, W. A. New insights into the biosynthetic logic of ribosomally synthesized and post-translationally modified peptide natural products. Cell Chem. Biol. 23, 31-44 (2016).

6. Schmidt, E. W. et al. Patellamide A and C biosynthesis by a microcin-like pathway in Prochloron didemni, the cyanobacterial symbiont of Lissoclinum patella. Proc. Natl Acad. Sci. USA 102, 7315-7320 (2005).

7. Oueis, E. et al. Derivatisable cyanobactin analogues: a semisynthetic approach Chembiochem 16, 2646-2650 (2015).

8. Houssen, W. E. et al. An efficient method for the in vitro production of azol(in) e-based cyclic peptides. Angew. Chem. Int. Ed. Engl. 53, 14171-14174 (2014).

9. Burkhart, B. J., Hudson, G. A., Dunbar, K. L. \& Mitchell, D. A. A prevalent peptide-binding domain guides ribosomal natural product biosynthesis. Nat. Chem. Biol. 11, 564-570 (2015).

10. Koehnke, J. et al. Structural analysis of leader peptide binding enables leaderfree cyanobactin processing. Nat. Chem. Biol. 11, 558-563 (2015).

11. Oueis, E., Jaspars, M., Westwood, N. J. \& Naismith, J. H. Enzymatic macrocyclization of 1,2,3-triazole peptide mimetics. Angew. Chem. Int. Ed. Engl. 55, 5842-5845 (2016)

12. Koehnke, J. et al. The mechanism of patellamide macrocyclization revealed by the characterization of the PatG macrocyclase domain. Nat. Struct. Mol. Biol. 19, 767-772 (2012).

13. Tianero, M. D. et al. Metabolic model for diversity-generating biosynthesis. Proc. Natl Acad. Sci. USA 113, 1772-1777 (2016).

14. Barber, C. J. et al. The two-step biosynthesis of cyclic peptides from linear precursors in a member of the plant family Caryophyllaceae involves cyclization by a serine protease-like enzyme. J. Biol. Chem. 288, 12500-12510 (2013).

15. Luo, H. et al. Peptide macrocyclization catalyzed by a prolyl oligopeptidase involved in alpha-amanitin biosynthesis. Chem. Biol. 21, 1610-1617 (2014).

16. Nguyen, G. K. et al. Butelase 1 is an Asx-specific ligase enabling peptide macrocyclization and synthesis. Nat. Chem. Biol. 10, 732-738 (2014).

17. Antos, J. M., Truttmann, M. C. \& Ploegh, H. L. Recent advances in sortasecatalyzed ligation methodology. Curr. Opin. Struct. Biol. 38, 111-118 (2016).

18. Nguyen, G. K. et al. Butelase 1: a versatile ligase for peptide and protein macrocyclization. J. Am. Chem. Soc. 137, 15398-15401 (2015).

19. Kohli, R. M., Trauger, J. W., Schwarzer, D., Marahiel, M. A. \& Walsh, C. T. Generality of peptide cyclization catalyzed by isolated thioesterase domains of nonribosomal peptide synthetases. Biochemistry 40, 7099-7108 (2001).

20. Li, K., Condurso, H. L., Li, G., Ding, Y. \& Bruner, S. D. Structural basis for precursor protein-directed ribosomal peptide macrocyclization. Nat. Chem. Biol. 12, 973-979 (2016).

21. Czekster, C. M. \& Naismith, J. H. Kinetic landscape of a peptide bond-forming prolyl oligopeptidase. Biochemistry 56, 2086-2095 (2017).

22. Pulman, J. A., Childs, K. L., Sgambelluri, R. M. \& Walton, J. D. Expansion and diversification of the MSDIN family of cyclic peptide genes in the poisonous agarics Amanita phalloides and A. bisporigera. BMC Genomics 17, 1038 (2016).

23. Barbato, M. P. Poisoning from accidental ingestion of mushrooms. Med. J. Aust. 158, 842-847 (1993)

24. Weerakkody, D. et al. Novel pH-sensitive cyclic peptides. Sci. Rep. 6, 31322 (2016).

25. Zanotti, G., Petersen, G. \& Wieland, T. Structure-toxicity relationships in the amatoxin series. Structural variations of side chain 3 and inhibition of RNA polymerase II. Int. J. Pept. Protein Res. 40, 551-558 (1992).

26. Walton, J. D., Hallen-Adams, H. E. \& Luo, H. Ribosomal biosynthesis of the cyclic peptide toxins of Amanita mushrooms. Biopolymers 94, 659-664 (2010).

27. Fulop, V., Bocskei, Z. \& Polgar, L. Prolyl oligopeptidase: an unusual betapropeller domain regulates proteolysis. Cell 94, 161-170 (1998). 
28. Canning, P., Rea, D., Morty, R. E. \& Fulop, V. Crystal structures of Trypanosoma brucei oligopeptidase B broaden the paradigm of catalytic regulation in prolyl oligopeptidase family enzymes. PLoS ONE 8, e79349 (2013).

29. Shan, L., Mathews, I. I. \& Khosla, C. Structural and mechanistic analysis of two prolyl endopeptidases: role of interdomain dynamics in catalysis and specificity. Proc. Natl Acad. Sci. USA 102, 3599-3604 (2005).

30. Szeltner, Z. et al. Substrate-dependent competency of the catalytic triad of prolyl oligopeptidase. J. Biol. Chem. 277, 44597-44605 (2002).

31. Harris, M. N., Madura, J. D., Ming, L.-J. \& Harwood, V. J. Kinetic and mechanistic studies of prolyl oligopeptidase from the hyperthermophile Pyrococcus furiosus. J. Biol. Chem. 276, 19310-19317 (2001).

32. Lone, A. M., Nolte, W. M., Tinoco, A. D. \& Saghatelian, A. Peptidomics of the prolyl peptidases. AAPS J. 12, 483-491 (2010).

33. Kaushik, S., Etchebest, C. \& Sowdhamini, R. Decoding the structural events in substrate-gating mechanism of eukaryotic prolyl oligopeptidase using normal mode analysis and molecular dynamics simulations. Proteins 82, 1428-1443 (2014).

34. Fulop, V., Szeltner, Z., Renner, V. \& Polgar, L. Structures of prolyl oligopeptidase substrate/inhibitor complexes. Use of inhibitor binding for titration of the catalytic histidine residue. J. Biol. Chem. 276, 1262-1266 (2001).

35 . Rydel, T. J. et al. The crystal structure, mutagenesis, and activity studies reveal that patatin is a lipid acyl hydrolase with a Ser-Asp catalytic dyad. Biochemistry 42, 6696-6708 (2003).

36. Koehnke, J. et al. The cyanobactin heterocyclase enzyme: a processive adenylase that operates with a defined order of reaction. Angew. Chem. Int. Ed. Engl. $\mathbf{5 2}$ 13991-13996 (2013)

37. Gettins, P. G. Serpin structure, mechanism, and function. Chem. Rev. 102, 4751-4804 (2002).

38. Oueis, E., Jaspars, M., Westwood, N. J. \& Naismith, J. H. Enzymatic macrocyclization of 1,2,3-triazole peptide mimetics. Angew. Chem. Weinheim Bergstr. Ger. 128, 5936-5939 (2016).

39. Oke, M. et al. The scottish structural proteomics facility: targets, methods and outputs. J. Struct. Funct. Genomics 11, 167-180 (2010).

40. Pace, C. N., Vajdos, F., Fee, L., Grimsley, G. \& Gray, T. How to measure and predict the molar absorption coefficient of a protein. Protein Sci. 4, 2411-2423 (1995).

41. Liu, H. \& Naismith, J. H. An efficient one-step site-directed deletion, insertion, single and multiple-site plasmid mutagenesis protocol. BMC Biotechnol. 8, 91 (2008).

42. Otwinowski, Z. et al. Processing of X-ray diffraction data collected in oscillation mode. Methods Enzymol. 276, 307-326 (1997).

43. Winter, G., Lobley, C. M. \& Prince, S. M. Decision making in xia2. Acta Crystallogr. D Biol. Crystallogr. 69, 1260-1273 (2013).

44. Storoni, L. C., McCoy, A. J. \& Read, R. J. Likelihood-enhanced fast rotation functions. Acta Crystallogr. D Biol. Crystallogr. 60, 432-438 (2004).

45. Zhang, K. Y., Cowtan, K. \& Main, P. Combining constraints for electrondensity modification. Methods Enzymol. 277, 53-64 (1997).

46. Cowtan, K. The Buccaneer software for automated model building. 1. Tracing protein chains. Acta Crystallogr. D Biol. Crystallogr. 62, 1002-1011 (2006).

47. Lamzin, V. S. \& Wilson, K. S. Automated refinement of protein models. Acta Crystallogr. D Biol. Crystallogr. 49, 129-147 (1993).

48. Emsley, P. \& Cowtan, K. Coot: model-building tools for molecular graphics. Acta Crystallogr. D Biol. Crystallogr. 60, 2126-2132 (2004).

49. Murshudov, G. N. et al. REFMAC5 for the refinement of macromolecular crystal structures. Acta Crystallogr. D Biol. Crystallogr. 67, 355-367 (2011).

50. Collaborative Computational Project, N. The CCP4 suite: programs for protein crystallography. Acta Crystallogr. D Biol. Crystallogr. 50, 760-763 (1994).
51. Afonine, P. V. et al. Towards automated crystallographic structure refinement with phenix.refine. Acta Crystallogr. D Biol. Crystallogr. 68, 352-367 (2012).

52. Joosten, R. P., Long, F., Murshudov, G. N. \& Perrakis, A. The PDB_REDO server for macromolecular structure model optimization. IUCrJ 1, 213-220 (2014).

53. Lamiable, A. et al. PEP-FOLD3: faster de novo structure prediction for linear peptides in solution and in complex. Nucleic Acids Res. 44, W449-W454 (2016).

54. Shen, Y., Maupetit, J., Derreumaux, P. \& Tuffery, P. Improved PEP-FOLD approach for peptide and miniprotein structure prediction. J. Chem. Theory Comput. 10, 4745-4758 (2014).

55 Chekan, J. R., Estrada, P., Covello, P. S. \& Nair, S. K. Characterization of the macrocyclase involved in the biosynthesis of RiPP cyclic peptides in plants. Proc. Natl. Acad. Sci. USA 114, 6551-6556 (2017)

56 Sgambelluri, R. M., Smith, M. O. \& Walton, J. D. Versatility of prolyl oligopeptidase B in peptide macrocyclization. ACS Synth. Biol. http://dx.doi.org/ 10.1021/acssynbio.7b00264 (2017)

\section{Acknowledgements}

H.L. is funded by the George \& Stella Lee Scholarship and Criticat EPSRC. This project was also funded by the European Research Council project 339367 NCB-TNT and by the BBSRC (K015508/1). J.H.N. is 1000 talent scholar of the Chinese Academy of Sciences at the University of Sichuan.

\section{Author contributions}

C.M.C. conceived the project, carried out experiments, interpreted data, and wrote the paper. S.A.M. and H.L. carried out experiments and interpreted data. J.H.N. conceived the project, interpreted data, and wrote the paper.

\section{Additional information}

Supplementary Information accompanies this paper at doi:10.1038/s41467-017-00862-4

Competing interests: The authors declare no competing financial interests.

Reprints and permission information is available online at http://npg.nature.com/ reprintsandpermissions/

Publisher's note: Springer Nature remains neutral with regard to jurisdictional claims in published maps and institutional affiliations.

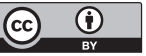

Open Access This article is licensed under a Creative Commons Attribution 4.0 International License, which permits use, sharing, adaptation, distribution and reproduction in any medium or format, as long as you give appropriate credit to the original author(s) and the source, provide a link to the Creative Commons license, and indicate if changes were made. The images or other third party material in this article are included in the article's Creative Commons license, unless indicated otherwise in a credit line to the material. If material is not included in the article's Creative Commons license and your intended use is not permitted by statutory regulation or exceeds the permitted use, you will need to obtain permission directly from the copyright holder. To view a copy of this license, visit http://creativecommons.org/ licenses/by/4.0/.

(C) The Author(s) 2017 